
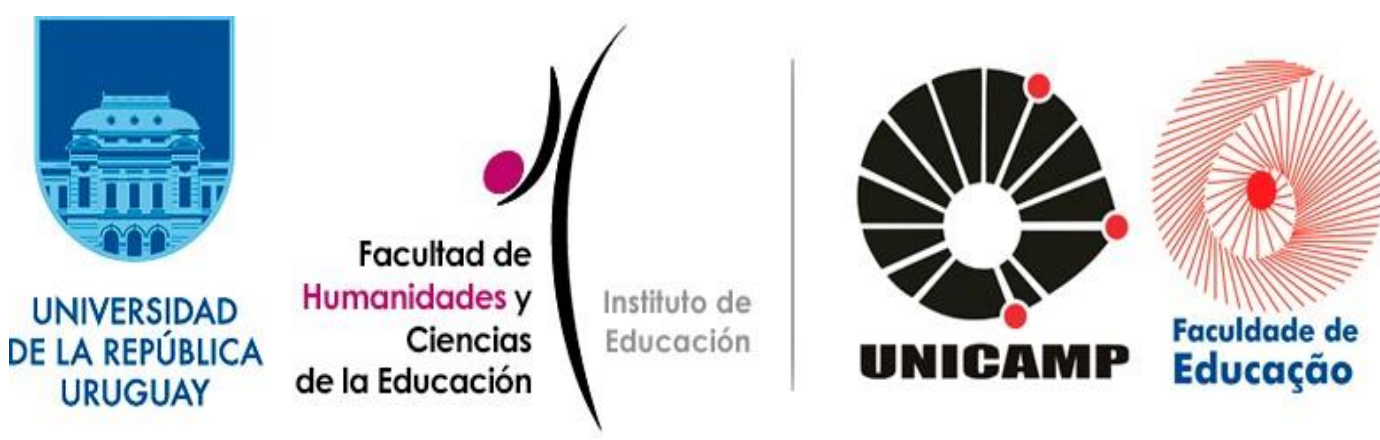

ESTUDIOS DE CASOS | ESTUDOS DE CASO

Fermentario V. 14, $\mathrm{N}^{\circ} 1(2020)$

ISSN 16886151

Instituto de Educación, Facultad de Humanidades y Ciencias de la Educación, Universidad de la República. www.fhuce.edu.uy

Faculdade de Educação, UNICAMP. www.fe.unicamp.br

¿De qué laicidad hablamos? Algunas ideas para discutir casos

actuales en la educación uruguaya

What secularism are we talking about? Some ideas to discuss

current cases in uruguayan education

Marina Camejo ${ }^{1}$

DOI: https://doi.org/10.47965/fermen.14.1.9

Recibido: $02 / 03 / 2020$

Aceptado: 19/05/2020

\title{
Resumen:
}

Si alguien ajeno a la educación uruguaya nos solicitara que caractericemos la educación uruguaya, inmediatamente responderíamos: laica, gratuita y obligatoria. Los elementos de esta triada no han sido discutidos ni ocupado el mismo lugar en los debates educativos actuales. La laicidad es quien ha ocupado un lugar más importante y sensible en los debates contemporáneos.

\footnotetext{
${ }^{1}$ Prof. de Filosofía egresada del Instituto de Profesores Artigas, Asistente Departamento de Historia y Filosofía de la Educación, Facultad de Humanidades y Ciencias de la Educación de la Universidad de la República.
} 
En este trabajo interesa discutir algunas ideas en torno al binomio laicidad-educación a partir de las pancartas que fueron colocadas en las fachadas de liceos públicos con el lema «La reforma no es la forma». Las pancartas generaron movimiento discursivo en la prensa y en la opinión pública, por lo que entendemos que una vez más es preciso que discutamos qué laicidad es posible predicar y qué margen para la libertad de expresión encontramos entre los estudiantes y en los centros educativos.

Palabras clave: laicidad, educación, libertad de expresión.

\begin{abstract}
If someone outside of Uruguayan education asked us to characterize uruguayan education, we would immediately respond: secular, free and obligatory. The elements of this triad have not been discussed or occupied the same place in current educational debates. Secularism is the one that has occupied a more important and sensitive place in contemporary debates.
\end{abstract}

In this paper, it is interesting to discuss some ideas about the secular-education binomial based on the banners that were placed on the facades of public lyceums with the slogan "The Reformation is not the way". The banners generated a discursive movement in the press and in public opinion, so we understand that once again it is necessary that we discuss what secularism it is possible to preach and what margin for freedom of expression we find among students and in educational centers.

Keywords: secularism, education, freedom of expression

Si alguien ajeno a la educación uruguaya nos solicitara que la caractericemos, inmediatamente responderíamos: laica, gratuita y obligatoria. Los elementos de esta triada no han sido discutidos ni ocupado el mismo lugar en los debates educativos actuales. La laicidad es quien ha ocupado un lugar más importante y sensible en los debates contemporáneos.

La idea de que Uruguay es un país laico se encuentra fuertemente arraigado en nuestra idiosincrasia y los uruguayos nos definimos como laicos. Hemos naturalizado lo que significa ser laicos y conformado a partir de ella un ethos sociocultural y una cosmovisión de la vida pública (Díaz Genis, 2019). A partir de esto resulta interesante señalar que creemos que ser laico es ser, pensar o actuar de determinada manera (en todo caso ello sería una laicidad a la uruguaya), máxime cuando podemos identificar que hay otras formas de entender y de vivir la laicidad lejanas a la nuestra e incluso incompatible en ciertos aspectos, según los contextos culturales e históricos. 
No hay una idea de laicidad univoca y tal vez sea por ello que aparezca como un fantasma amenazante en discusiones en torno a problemas educativos o problemas en la educación que en algunos casos implicaría la supuesta violación de la laicidad. Es interesante notar como la apelación a la violación de la laicidad como argumento aparece en aquellos debates de carácter ideológico, es decir, cuando temas sensibles desde la perspectiva ideológica inundan o amenazan con irrumpir en la escena educativa. Es preciso que discutamos de qué laicidad estamos hablando y qué implica o no violar o transgredir la laicidad.

Podemos indicar momentos en los que han resurgido discusiones donde la laicidad vuelve a ser protagonista. Uno de estos momentos ocurrió durante el período 2005-2008 alrededor del debate sobre la enseñanza de la historia reciente, en el 2017 reaparece en la discusión en torno a la educación en derechos humanos vinculados a las identidades de género, en este 2019 reaparece a partir de pancartas colocadas por estudiantes liceales en algunos centros educativos de educación media. ${ }^{2}$ Por supuesto, que estos son solo algunos casos donde la laicidad y lo que ella implica se instala en el terreno educativo, no obstante, lo relativo a la laicidad no se reduce a la educación y se expande a otros terrenos de los que también deberíamos ocuparnos.

Creo pertinente señalar, previo a una discusión en términos más actuales, qué sentidos se le adjudicaban al concepto de laicidad o de enseñanza laica a principios del siglo XX hasta la década del setenta aproximadamente. Gerardo Caetano y Roger Geymonat (1997) han señalado que el éxito del proceso de secularización anticlerical promovido por el estado batllista hunde sus raíces en el siglo anterior. Sería adecuado hurgar en la historia de las últimas décadas del siglo XIX, pues allí se gestaron discusiones de las que emergieron tensiones y que provocaron que la laicidad se estructurara de cierta forma que impactaron en el siglo XX.

También resulta necesario diferenciar entre los conceptos de laicidad y de secularización. Por este último, puede entenderse que en el mundo occidental el proceso de secularización ha tenido que ver con la emergencia de contextos más plurales en la modernidad y la pérdida de eficacia de las religiones como «cosmovisiones totalizantes y globales» proveedoras de sentido. «Esta "crisis de

\footnotetext{
${ }^{2}$ Las pancartas rezan «La reforma no es la forma» en una clara alusión a la reforma constitucional impulsada por el líder nacionalista Jorge Larrañaga quien lleva adelante una campaña denominada «Vivir sin miedo». Entre los puntos contemplados y que interesa destacar en este proyecto de reforma se encuentra a) quien cometa delitos graves, no podrá recibir beneficios libertarios y deberá cumplir la pena en su totalidad, b) el proyecto de reforma prevé habilitar que la ley le dé derecho a los jueces para que cuando haya sospechas puedan ordenar allanamientos nocturnos para combatir la delincuencia en horas de la noche, c) el proyecto de reforma prevé crear la reclusión permanente revisable como forma de mitigar la delincuencia aberrante o de tener bajo control y castigo a los delincuentes de difícil o imposible recuperación. Estos permanecerían durante treinta años recluidos, y una vez demostrada su rehabilitación recuperarían su libertad, d) creación de una guardia nacional de militares. En https://vivirsinmiedo.com.uy/.
} 
credibilidad" de las religiones institucionales se vio estimulada así por la irrupción acelerada de «nuevos procesos de nominación», provenientes de las segmentación social y simbólica de las sociedades modernas» (Caetano y Geymonat, 1997, p. 27).

En el caso de Uruguay, el proceso de secularización ocurre entre 1859 y 1919. Este período está marcado por la llegada de Jacinto Vera como Vicario y su intento de reformar a la Iglesia en Uruguay de acuerdo a los lineamientos del Vaticano, y la entrada en vigencia de la Constitución en la que el Estado se separa oficialmente de la Iglesia. Caetano y Geymonat advierten que hacia 1919 el proceso no se encontraba cerrado, sino que para esa fecha había una cierta estructuración entre Estado e Iglesia, público y privado, política y religión, que va a marcar a la sociedad uruguaya del resto del siglo XX. Es destacable de ese proceso: la secularización de los cementerios en 1861, la Ley de Educación Común de 1877, el Registro Civil en 1879, y el matrimonio civil en 1885.

Puede señalarse que, a mediados del siglo XIX, no había en Uruguay un Estado plenamente consolidado que desplazara a la Iglesia, pero tampoco se trataba de una Iglesia poderosa con la que hubiese que disputar. Así, poco a poco, el Estado fue ganando espacios que antes le correspondían a la Iglesia, aunque estaba instalado un conflicto entre dos instituciones más o menos paritarias que «a la vez que procuran reformarse y afianzarse, chocan por la delimitación y ocupación de un espacio público en construcción» (Caetano y Geymonat, 1997, p. 44).

Dos son las tesis principales que Caetano y Geymonat esgrimen sobre el tema y que se sustentan en investigaciones de José Pedro Barrán. La primera tesis consiste en afirmar que el proceso de secularización implicó una privatización de lo religioso. Esto debe entenderse como consecuencia de que en la paulatina diferenciación entre lo público y lo privado las manifestaciones de las instituciones religiosas y de la vida religiosa fueron quedando relegadas a la vida privada. La segunda tesis nos pone en contacto con la idea de que en forma paralela se dio una transferencia de la sacralidad de lo religioso a lo político. Esto junto con la conformación de un «religión civil» o «moral laica», con su simbología, rituales y liturgias alternativas, orientadas a reforzar la identidad y el orden social.

Escapa a nuestras posibilidades determinar qué tipo de laicidad es la que se vive en Uruguay, máxime cuando podemos detectar que la laicidad como fenómeno se ha ido transformando. Sin embargo, puede ser valioso recordar que hay diferentes tipologías de laicidad. Caetano (2013, p. 120) apela a la tipología elaborada por Michele Milot, según la cual pueden reconocerse laicidades que son separatistas, anticlericales, autoritarias, de fe cívica, y de reconocimiento, ante esto Caetano concluye 
ue «el modelo clásico de laicidad en el caso de la historia uruguaya sería una mezcla de los prototipos “separatista", "anticlerical”, y "de fe cívica”».

Néstor da Costa reconoce tres categorías de posturas ante la laicidad por parte de diferentes actores en Uruguay, se trata de una posición intransigente, una posición plural y una tercera posición negadora. La posición intransigente se caracteriza «por un prejuicio antirreligioso, refiriéndose a lo religioso en términos de oscurantismo e ignorancia, negando cualquier tipo de reconocimiento a lo religioso en el sistema educativo público, y manifestando un claro prejuicio anticlerical» (2009, p. 146). La posición plural es aquella que defiende la necesidad de mantener separados los asuntos confesionales del Estado y lo educativo. Esta posición reconoce que en el ámbito educativo se debe salir de una actitud de ignorancia y prescindencia de lo religioso como fenómeno social, y acepta la inclusión de lo religioso en el sistema educativo sin que suponga ningún grado de confesionalización (2009, p. 147). Por último, encontramos la posición negadora de la laicidad que reclama la inclusión de cierta confesionalidad en el espacio público por lo que se trata de una posición muy cercana al antimodernismo» (2009, p. 147).

A grandes rasgos podemos decir que desde fines del siglo XIX hasta mediados del siglo XX (a pesar de las grandes diferencias que sería posible detallar pero que no haremos aquí) los debates en torno a la laicidad se realizan en el contexto del proceso secularizador (donde lo que está en juego es la relación Estado- iglesia), mientras que aproximadamente desde la década de los años sesenta el concepto de laicidad comienza a adquirir connotaciones más conservadoras y a ser usado para combatir el ataque marxista. Podemos decir que esta nueva connotación que adquiere el concepto ocurre en el contexto de debates políticos-ideológicos. Dichos debates se intensificaron en el período previo al golpe de Estado de 1973, allí el concepto fue debatido con fuerza en relación con su significado y en relación con el papel de la docencia (Alvez Cavanna, Faget y Batista, 2017, p. 79).

La hipótesis que propone Alvez Cavanna (2013) consiste en afirmar que la laicidad en nuestro país, en el contexto de la Guerra Fría y en el marco de la doctrina de seguridad nacional (DSN) pasó a significar principalmente ausencia de marxismo y neutralidad absoluta por parte del Estado, lo característico de este proceso es el abandono paulatino de las cuestiones vinculadas a la religión para pasar a ocuparse o centrarse en cuestiones acerca de ideología política.

La tesis propuesta por Federico José Alvez Cavanna (2013) respecto a una noción de «laicidad conservadora» o «ajustista» o «adecuacionista» como le llamó Carlos Real de Azúa (1992) pervive aun entre nosotros y resulta determinante para pensar cómo impacta en el seno de la educación, en el 
rol docente y en los procesos de enseñanza la incorporación de ciertas temáticas. Puede señalarse que, en el centro de los debates acaecidos en nuestro país, el concepto de laicidad se ha ido transformando en algo «sagrado» en la cultura y en la terminología política en el transcurso del siglo XX. Esto encierra una paradoja, pues defender la laicidad parece ser el escenario desde el que todas las voces son defendidas y por ende habilitadas una vez que se rompe la relación Estado- religión, y el Estado se muestra neutro frente a diversas posiciones, ideologías, perspectivas, etc.; sin embargo, al irse transformando la laicidad en algo «sagrado» lo que se desprende es de eso no podemos hablar. Es así como en el campo educativo no podemos introducir lo político, lo religioso, la ideología de género o la enseñanza de la historia reciente sin ser acusados de violar la laicidad.

Dirimir qué actos son proselitistas y qué actos no lo son parece ser crucial para comprender por un lado si se está incurriendo en violación de la laicidad y por otro lado si se está garantizando la libertad de pensamiento, de conciencia, de expresión y de manifestación de los sujetos. Asimismo, la libertad de expresión está fuertemente relacionada con la libertad de pensamiento y/o de conciencia, incluso podría entenderse que aquella es consecuencia de esta, en el sentido de que la conducta, la forma de vivir, la forma de sentir o de ser se derivan de cómo se piensa o se vive una religión o ideología determinada. Parte de esto es lo que está en juego en el caso de las pancartas colocadas por estudiantes en el Liceo n. ${ }^{\circ} 28$ de Montevideo, conducta que fue replicada por los gremios estudiantiles de otros liceos públicos de la citada ciudad. En dichas pancartas aparece «Si querés seguridad no pidas militares, pedí educación. La reforma no es la forma». La Justicia ordenó a la Administración Nacional de Educación Pública (ANEP) el retiro de los carteles, alegando que «no se pretendía generar un conflicto» pero sí que se respeten los «derechos constitucionales de las personas y su irrestricta vigencia». La jueza en lo Contencioso Administrativo de Primer Turno que falló este caso, la Dra. María Carmen Reyes consideró que los mensajes en los carteles son «de neto corte político» y «constituyen sin duda actividad proselitista». Asimismo, la magistrada agregó que la «tolerancia» de las autoridades de la ANEP frente a los carteles es «una conducta omisiva manifiestamente ilegítima que conculca el principio de laicidad» (La Diaria, 2019b).

La justicia entró en acción una vez que el diputado Pablo Abdala (legislador del sector Alianza Nacional que promovió la reforma) denunciara que las pancartas en las fachadas de los centros educativos violaban la laicidad.

La denuncia llevada adelante por Abdala se sustenta en que «no se puede poner un cartel en el espacio público porque compromete al Estado y a todos los vinculados al centro de estudio independientemente que estén a favor o en contra de esta posición» (Fripp, 2019). 
Este es el marco desde el que nos sentimos interpelados desde la filosofía de la educación a discutir este caso concreto pues entendemos que aparecen en él ciertos elementos que deben ser aclarados pues en juego se encuentran nuestras libertades. En este caso puede identificarse con claridad que la disputa en torno a la violación de la laicidad se da en términos ideológicos, esto último implica considerar que pronunciarse desde instituciones educativas en contra de ciertas reformas constitucionales es hacer proselitismo.

En primer lugar, podríamos detenernos en aclarar si la presencia de las pancartas en las fachadas de los edificios educativos implica proselitismo. Desde cierta perspectiva podríamos considerar que así es, en tanto la pancarta insta a no apoyar un proyecto de reforma constitucional que está fuertemente relacionado con un partido político determinada ya que este es quien la impulsa. Pero desde otra perspectiva, no puede aceptarse que es un acto proselitista puesto que este alude a cuando una persona y/o una institución tratan de convencer y ganar seguidores o partidarios para una causa o una doctrina. No parece ser que busquen ganar seguidores sino expresar una postura como gremio estudiantil.

En segundo lugar, parece pertinente detenerse en qué tan involucrada o comprometida se encuentra la institución con lo que la pancarta expresa. En la medida en que la pancarta se encuentra firmada por el gremio estudiantil del Liceo $\mathrm{n}^{\circ} 28$ esto no dañaría la imagen ni la reputación de la institución, no obstante, surge el problema de la representatividad de ese gremio y de si representa el sentir y pensar de los jóvenes que pertenecen al centro educativo. La pancarta no representa a la institución liceal, representa a un gremio cuya voz no representa necesariamente a las voces de la población del Liceo n. ${ }^{\circ} 28$ y esto nos conduce a introducir otro elemento en la discusión que no es menor. ¿Cuál es el mejor lugar para colgar una pancarta: la fachada del liceo o la cartelera gremial? Tal vez la discusión se reduzca a qué espacios son los legítimos para llevar a cabo estos procesos. Pero que se coloque en una cartelera genera menos efecto pues solo es visible a quienes circulan por la institución más no evita el problema de caer en violación de laicidad. Que no sea accesible al público no significa que no se esté dañando o coartando las posibles expresiones que sobre el tema se susciten.

Nos sentimos convocados a defender la autonomía del pensamiento y la laicidad en el contexto de la defensa de los derechos humanos. No es cualquier laicidad y a cualquier precio la que debe ser defendida sino aquella que reconozca la diferencia y la defienda como tal. En este sentido podemos aunarnos a lo afirmado por Jocelyn Maclure y Charles Taylor (2011) al afirmar que la laicidad es un tipo de gobernanza asentada sobre ciertos principios que son la libertad de conciencia y la igualdad de valor moral de los ciudadanos. Estos principios para ser llevados a cabo necesitan de la separación entre Estado y religión, aunada a la neutralidad religiosa del Estado. Sin embargo, suele darse lo que 
ellos llaman «el fetichismo de los medios» producto de la confusión entre los medios y los fines. Es así como en un modelo de laicidad tipo republicano (Uruguay sería el caso) los medios pasan a ser fines. La laicidad es un medio para el reconocimiento de la diferencia, para la valoración y respeto de la diferencia, pero una vez que se asume como fin, el resto queda enmascarado y promueve a mi entender conductas intransigentes.

Es en este sentido, que podemos pensar que se asume una postura intransigente (Da Costa lo menciona en función de lo religioso, pero creo que podríamos extenderlo a lo político) cuando se vedan ciertas expresiones o pronunciamientos. Tal es el caso de lo sucedido con las pancartas colocadas en el Liceo $\mathrm{n}^{\circ} 28$.

Me sumo a las palabras de Tabaré Vázquez en su discurso pronunciado en la Gran Logia de la Masonería del Uruguay «la laicidad es un marco de relación en el que los ciudadanos podemos entendernos desde la diversidad, pero en igualdad. La laicidad es garantía de respeto al semejante y de ciudadanía en la pluralidad. O dicho de otra manera: la laicidad es factor de democracia». ${ }^{3}$

Si la laicidad es factor de democracia entonces ella debe promover y garantizar el respeto a la dignidad humana, el respeto, la autonomía y la capacidad de decisión. Porque además la democracia no solo es un modelo político sino ante todo un modelo pedagógico pues las diferencias tienen lugar en ella para ser y para expresarse.

Frente a la voz de la magistrada Reyes que resolvió que las pancartas debían ser eliminadas se alzaron las voces de los docentes de la Universidad de la República y agremiados en la Federación Nacional de Profesores de Educación Secundaria (Fenapes) en un claro respaldo a los estudiantes alegando que se observaba una inadecuada judicialización del tema y se alertaba sobre la restricción a la libertad de pensamiento (La Diaria, 2019b). Lo que los docentes subrayan es el rechazo a las estrategias políticas de judicialización de los razonables desacuerdos que tenemos por vivir en sociedades plurales; especialmente si la judicialización supone forzar una interpretación normativa excesivamente restrictiva de la libertad de expresión de las asociaciones gremiales.

El problema en este caso es la inclusión de lo político en lo educativo, pero pretendo defender que se maneja una idea de hacer política restringido a lo «partidario» cuando hacer política es una cuestión de todo aquel que forme parte de la polis y que desde esta perspectiva todo estudiante tiene la libertad para manifestarse a favor o en contra de propuestas políticas partidarias. No obstante, se acepta la objeción de que la línea divisoria entre libertad de expresión (que puede coincidir o no con

\footnotetext{
${ }^{3}$ Discurso de Tabaré Vázquez en la Gran Logia de la Masonería, 14 de julio de 2005 (Uruguay, 2005).
} 
expresiones políticas partidarias) y hacer campaña política es endeble. Parece necesario educar para discernir respecto a cuáles son los espacios desde los que pronunciarnos políticamente, sin olvidar que la educación es esencialmente política.

Asimismo, entiendo que en muchos de nosotros estas pancartas motiven el desacuerdo por ser pronunciamientos en contra de una campaña política y que se aluda por ello a violación de la laicidad, mientras que en muchos otros de nosotros genere simpatía por comulgar con nuestras creencias más férreas. Sin embargo, el meollo del asunto es el espacio de libertad. Sentimos que judicializar la iniciativa de los estudiantes es limitar la expresión porque entendemos que la campaña no promueve la convivencia pacífica o la desestigmatización, sino que por el contrario continúa etiquetando a ciertos tipos de sujetos como delincuentes o criminales. Desde la campaña se promueve la legitimación de la represión y/o de la mera sospecha sobre el acto delictivo lo que entre otras razones que podrían manejarse atentan contra el respeto a la libertad y quebrantan la posibilidad de educar para la convivencia. Pero más allá de qué proponga el proyecto de reforma, lo que está en juego es la posibilidad de pronunciarse en su contra desde la educación pública. Claro está que si estamos abogando por la laicidad lo primero que deberíamos reclamar es la presencia de todas las voces que tengan algo que decir sobre el tema. Si es que entendemos la laicidad como pluralidad de visiones y de concepciones de vida. E incluso si defendemos a la laicidad como neutralidad no en relación con lo religioso como tradicionalmente ha sido entendida sino neutralidad política (partidaria), ya que por el contrario defendemos que desde ella se asuman compromisos con los diversos aspectos y dimensiones que hacen a la vida en la polis. Asumidas estas premisas, entonces, no debería escandalizarnos que también pudieran alzarse pancartas que recen a favor de la campaña Vivir sin Miedo. Pero no parece ser esta una opción viable. Tal vez la razón se sustente en que solo podemos habilitar y reconocer como voces a aquellas voces que no atenten contra los derechos humanos y que por tanto afirmen la dignidad del ser humano sin caer en etiquetar conductas a partir de sus ideas/concepciones/ideologías/creencias.

La laicidad debe ser concebida como la acogida democrática de todas las formas de vida y por ello parece necesario (más allá de evitar confundir medios con fines) tener en el horizonte lo que Adela Cortina (1986) diferencia como valores que pertenecen a una ética de mínimos y valores que pertenecen a una ética de máximos. Los valores de esta última son los que apuntan a alcanzar la felicidad como fin de la vida humana y que pueden o están relacionados con múltiples formas que cada individuo adopta. Por otro lado, la ética de mínimos alude a los valores necesarios para que todas esas éticas de máximos puedan coexistir en armonía. Entre sus valores encontramos a la igualdad, el 
respeto, la libertad, la solidaridad, el diálogo, etc., valores que son promovidos desde la democracia porque hacen a ella, a la vez que la sustentan y se despliegan en ella.

Cuando se judicializa una situación como a la que venimos refiriendo, estamos optando por ciertos valores que se justifican desde el entendido de que la laicidad está en riesgo. Mas cuando un gremio estudiantil o docente defiende su derecho a expresarse lo que debemos resaltar es que la libertad de expresión no linde con lo deshumanizante ni con lo degradante. Por otro lado, forma parte de la laicidad promover el pensamiento crítico y el compromiso político entendido como el compromiso con la reflexión sobre forma de vida y convivencia junto a otros. Desde la educación y desde la filosofía de la educación hemos de promover la reflexión sobre qué tipo de sociedad queremos y por ello parece pertinente apoyar que los estudiantes se pronuncien sobre cuestiones que más tarde o temprano impactaran en la organización de nuestra sociedad y que promoverá determinadas formas de vida y valores en desmedro de otros. Sin embargo, desde la educación y desde el lugar de educadores no nos corresponde promover ni proponer que cierta forma de vida es mejor que otra, pero sí debemos pensar ¿cómo vamos a promover la igualdad y el respeto a la diferencia si no conocemos las razones por las que los otros proponen lo que proponen?, ¿cómo vamos a construir una mejor sociedad si no hay lugar para el diálogo?, ¿cómo discutir desde la laicidad y para el fortalecimiento de la laicidad sin reconocer o dar voz al que no comparte mis ideas y/o mi forma de vida?, ¿cómo fortalecer la humanidad si no hay lugar para el pensamiento alternativo?, ¿cómo contribuir desde la educación para forjar espacios desde los que habilitar la libertad de pensamiento?

\section{Lista de Referencias}

Alvez Cavanna, F. (2013). História do conceito de laicidade no uruguai: do batllismo à doutrina da segurança nacional (1903-1972). (Tesis Doctoral). Curitiba: Universidade Federal do Paraná.

Faget, G. y Batista, P. (2017). El redil del concepto de laicidad “ajustista”. En: Diogo da Silva Roiz (Org.). A prática da história intelectual e dos intelectuais. Ideias, movimentos e ações. Jundiaí: Paco Editorial.

Caetano, G. y Geymonat, R. (1997). La secularización uruguaya (1859-1919). Catolicismo y privatización de lo religioso. Montevideo: Taurus.

Caetano, G. y Geymonat, R. (2013). El «Uruguay Laico». Matrices y revisiones. Montevideo: Taurus.

Cortina, A. (1986). Ética mínima. Introducción a la filosofía práctica. Madrid: Tecnos.

Da Costa, N. (2009). La laicidad uruguaya. Archives de Sciences Sociales des Religions, (146), 137-155. Recuperado de https://journals.openedition.org/assr/21270.

Díaz Genis, A. (2019, junio 3). ¿Qué le cabe a la laicidad hoy? La Diaria. Recuperado de https://ladiaria.com.uy/articulo/2019)6/que-le-cabe-a-la-laicidad-hoy/. 
Fripp, N. (2019, mayo 31). Abdala denuncia «violación de la laicidad en el liceo 28. 970 AM Universal. Recuperado de https://970universal.com/2019/05/31/abdala-denuncia-violacion-de-la-laicidad-en-el-liceo-28/.

La Diaria (2019a, junio 26). La justicia ordenó a la ANEP retirar los carteles contra la reforma Vivir sin Miedo de los liceos. La Diaria, Recuperado de http://educacion.ladiaria.com.uy/articulo/2019/6/la-justicia-ordeno-a-la-anepretirar-los-carteles-contra-la-reforma-vivir-sin-miedo-de-los-liceos/.

(2019b, julio 20). Udelar rechaza «estrategias políticas de judicialización» que supongan restricciones a la libertad de expresión. La Diaria. Recuperado de https://findesemana.ladiaria.com.uy/articulo/2019/7/udelarrechaza-estrategias-politicas-de-judicializacion-que-supongan-restricciones-a-la-libertad-de-expresion/.

Maclure, J. y Taylor, C. (2011). Laicidad y libertad de conciencia. Madrid: Alianza Editorial.

Real de Azúa, C. (1992). La Universidad. Montevideo: Celadu.

Uruguay. Presidencia República Oriental del Uruguay (2005, julio 14). Vázquez: laicidad, como garantía de respeto y pluralidad, es factor de democracia. Recuperado de http://archivo.presidencia.gub.uy/_web/noticias/2005/07/2005071404.htm. 